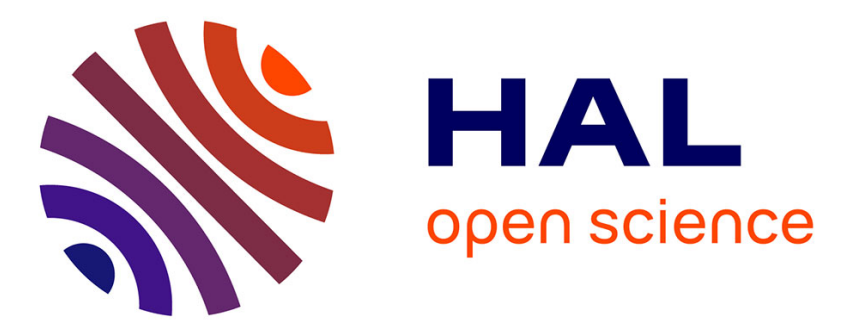

\title{
Measurement of the Soret, diffusion, and thermal diffusion coefficients of three binary organic benchmark mixtures and of ethanol/water mixtures using a beam deflection technique
}

Andreas Königer, Börn Meier, Werner Köhler

\section{To cite this version:}

Andreas Königer, Börn Meier, Werner Köhler. Measurement of the Soret, diffusion, and thermal diffusion coefficients of three binary organic benchmark mixtures and of ethanol/water mixtures using a beam deflection technique. Philosophical Magazine, 2009, 89 (10), pp.907-923. 10.1080/14786430902814029 . hal-00514015

\author{
HAL Id: hal-00514015 \\ https://hal.science/hal-00514015
}

Submitted on 1 Sep 2010

HAL is a multi-disciplinary open access archive for the deposit and dissemination of scientific research documents, whether they are published or not. The documents may come from teaching and research institutions in France or abroad, or from public or private research centers.
L'archive ouverte pluridisciplinaire HAL, est destinée au dépôt et à la diffusion de documents scientifiques de niveau recherche, publiés ou non, émanant des établissements d'enseignement et de recherche français ou étrangers, des laboratoires publics ou privés. 


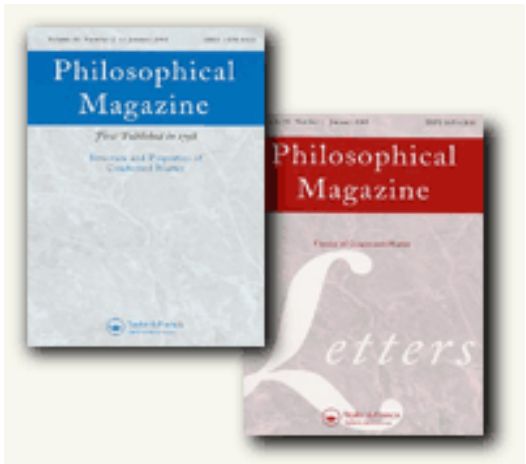

\section{Measurement of the Soret, diffusion, and thermal diffusion coefficients of \\ three binary organic benchmark mixtures and of ethanol/water mixtures using a beam deflection technique}

\begin{tabular}{|r|l|}
\hline Journal: & Philosophical Magazine \& Philosophical Magazine Letters \\
\hline Manuscript ID: & TPHM-09-Jan-0010.R1 \\
\hline Journal Selection: & Philosophical Magazine \\
\hline Date Submitted by the \\
Author: & 04-Feb-2009 \\
\hline Complete List of Authors: & $\begin{array}{l}\text { Königer, Andreas; Univ. Bayreuth } \\
\text { Meier, Börn; LMU München } \\
\text { Köhler, Werner; Univ. Bayreuth }\end{array}$ \\
\hline Keywords: & diffusion, thermal transport \\
\hline Keywords (user supplied): & Soret effect \\
\hline &
\end{tabular}

\section{S ScholaroNE" \\ Manuscript Central}


Philosophical Magazine

Vol. 00, No. 00, 00 Month 200x, 1-14

\title{
RESEARCH ARTICLE
}

\author{
Measurement of the Soret, diffusion, and thermal diffusion \\ coefficients of three binary organic benchmark mixtures and of \\ ethanol/water mixtures using a beam deflection technique
}

\author{
A. Königer, B. Meier ${ }^{\dagger}$, and W. Köhler* \\ Physikalisches Institut, Universität Bayreuth, D-95440 Bayreuth \\ (Received 00 Month 200x; final version received 00 Month 200x)
}

\begin{abstract}
We have measured Soret $\left(S_{T}\right)$, diffusion $(D)$, and thermal diffusion $\left(D_{T}\right)$ coeffcients of the three binary mixtures of dodecane (DD), isobutylbenzene (IB) and 1,2,3,4tetrahydronaphthalene (TH) for a concentration of $50 \mathrm{wt} \%$ at a temperature of $25^{\circ} \mathrm{C}$ by means of an optical beam deflection cell. This relevant experimental technique was still missing from a recent benchmark campaign for the measurement of the Soret effect. The measured coefficients agree to within a few percent $\left(10 \%\right.$ for $S_{T}, D$ of TH/IB) with the proposed benchmark values. A detailed analysis of the measurement process of the beam deflection cell, which allows for an elegant extension to include temperature gradients within the windows, is given and improved benchmark values are suggested. In addition, ethanol/water mixtures have been investigated very carefully over a broad concentration and temperature range. Comparison with data of Kolodner and Wiegand gives a generally good agreement with some systematic deviations. Contrary to theoretical predictions, we have not been able to identify a second sign change of $S_{T}$ at high ethanol concentrations.
\end{abstract}

\section{Introduction}

Off-diagonal transport processes in multicomponent fluids with both temperature and concentration gradients have recently gained growing attention. In particular the Soret effect, which describes the occurrence of a diffusive mass flow that is driven by a temperature difference, has been discussed in the context of such diverse phenomena as the composition of crude oil reservoirs and the magmatic differentiation on geological time scales (for references see [1]), analytical polymer fractionation [2, 3], convective instabilities [4], or prebiotic evolution [5]. Although the effect itself has been known already for more than a century since the pioneering works of Ludwig [6] and Soret [7], the measurement of reliable data turned out to be rather difficult. Over time, a number of different experimental techniques have been developed, and even microgravity experiments have been performed [8] with the aim to circumvent problems arising from unwanted convection. Despite all these efforts, the experimental data basis is still rather small and often inconsistent when compared to diagonal transport properties, such as the isothermal diffusion coefficient. In particular, until recently, there were hardly any data that had independently been confirmed by different researchers and that could serve as reference data for the test of existing and novel experimental techniques.

Starting in the year 2000 a joint effort was undertaken to resolve this problem and to provide reliable benchmark values for the Soret, diffusion and thermal diffusion coefficients of the three binary mixtures of dodecane, isobutylbenzene, and

\footnotetext{
${ }^{\dagger}$ present address:Department für Physik, Ludwig-Maximilians-Universität, D-80539 München

*Corresponding author. Email: werner.koehler@uni-bayreuth.de 
1,2,3,4-tetrahydronaphthalene for a concentration of $50 \mathrm{wt} \%$ at a temperature of $25^{\circ} \mathrm{C}[9]$. The experimental techniques employed by the five participating laboratories were transient holographic gratings [10, 11], annular and parallelepipedic thermogravitational columns [12], vertical parallelepipedic columns with velocity amplitude determination by laser Doppler velocimetry [13], and an annular thermogravitational column filled with a porous medium in the gap [14]. The various thermogravitational column techniques are based on the coupling of convection and diffusion. Detection and analysis can either be accomplished by sample extraction and external density or refractive index measurement or in-situ by optical measurement of the velocity profile. In either case the temperature gradient is imposed by the boundary condition of different wall temperatures. The holographic grating technique of thermal diffusion forced Rayleigh scattering (TDFRS), on the other hand, is all-optical and convection-free [15]. Here, laser beams are used not only for detection but also for formation of the temperature gradients by periodic heating throughout the sample volume, which is a thin liquid layer of typically 100 micrometer thickness. Compared to all other techniques, the diffusion length is in the micrometer range, resulting in very rapid sub-second equilibration times. In recent years two new techniques, which combine electrical heating at the boundary with optical detection and short diffusion lengths $[16,17]$ have been developed and successfully tested with the benchmark systems (Refs. [16, 17] and Ref. 75 in [18]).

As explicitly stated in the publication of the benchmark results, the "techniques employed by the participating laboratories cover all standard techniques for measuring the Soret coefficient with one exception, the diffusion cell experiments" [9]. Diffusion cells with a vertical temperature gradient between two parallel horizontal metal plates and optical detection were already used by Meyerhoff and Nachtigall, who employed a Schlieren technique [19, 20]. Later, Giglio and Vendramini [21, 22], Kolodner et al. [23], Zhang et al. [24, 25], and Piazza et al. [26] utilized the deflection of a laser beam by the refractive index gradient within the cell for detection. A comprehensive theory of the thermal diffusion problem between two parallel plates has been developed by Bierlein [27]. Diffusion cells belong to the class of convection-free experiments with optical detection and temperature gradients prescribed by the boundary conditions, that was completely missing from the benchmark campaign.

Besides the benchmark systems, ethanol/water is one of the most intensely studied binary mixtures and has served as a model system for double-diffusive convection experiments [4, 28]. A number of authors have measured the Soret coefficient, which shows an interesting sign change at an ethanol concentration of approximately $29 \mathrm{wt} \%$ [23, 25, 29]. Microgravity experiments have been performed, but no agreement with ground based measurements was achieved $[8,30]$.

The most complete study of the Soret coefficient of ethanol/water is the one of Kolodner et al. [23], who employed a diffusion cell with optical beam deflection. This very careful study is one of the most often cited publications in the field of thermal diffusion and the published data have often been regarded as reference values by other authors.

The purpose of the present study is twofold. First, we describe the employed beam deflection setup in detail. With this new instrument we have repeated and extended the study of Kolodner, thereby improving the literature data for certain parameter ranges and searching for a predicted second sign change of the Soret coefficient $S_{T}$ at high ethanol concentrations [31,32]. Second, we have used the setup to supply the missing beam deflection data for the benchmark mixtures of dodecane, isobutylbenzene, and 1,2,3,4-tetrahydronaphthalene. 


\section{bruary 4,2009
Page 3 of $\mathbf{1 4}$}

\section{1}

4

5

8

9

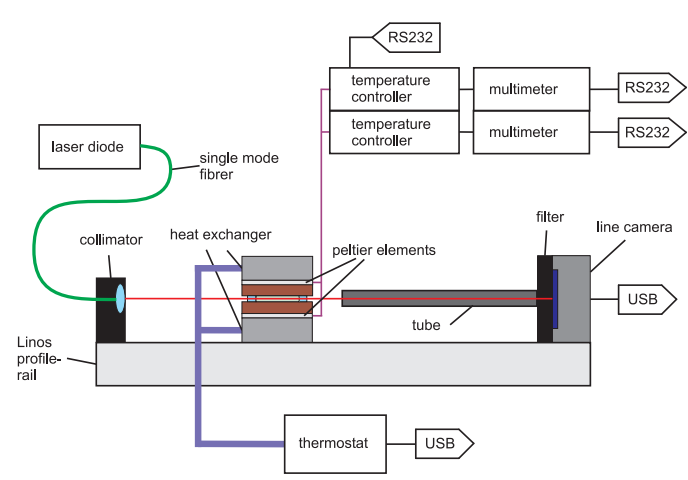

(a)

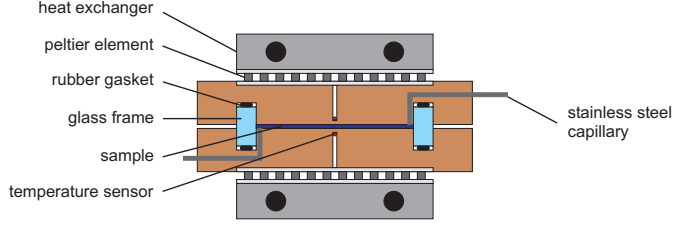

(b)

Figure 1. a) Overview of the beam deflection setup. b) Cross section of the cell.

\section{Experimental}

A schematic drawing of the beam deflection setup is shown in Fig. 1(a). The instrument has been built, with some modifications, according to the one operated in the group of Piazza [26, 33]. In order to learn the operation of the instrument, one of us (BM) had the oportunity to spend some time at the Politecnico di Milano. All components are mounted on an aluminum profile rail (Linos X95). Due to its $\mathrm{X}$-shaped geometry, the rail is particularly stiff and provides a high long-term stability with typically $11 \mathrm{~nm} / \mathrm{h}$ beam drift at the detector. The rail has a length of $2 \mathrm{~m}$ and is placed, well balanced and mechanically decoupled, on top of an optical table.

$50 \mathrm{~cm}$ from the left edge of the rail, the cell is sandwiched between two Peltier elements (Conrad Electronic, TEC 1-12714, $P_{\max }=135 \mathrm{~W}, I_{\max }=14 \mathrm{~A}$ ). The sides of the Peltier elements facing away from the sample are in tight contact to aluminum heat exchangers, which are kept at constant temperature by a circulating water bath (Julabo F32). The whole stack is clamped together within a U-shaped aluminum bracket by means of two coil springs.

A close-up view of the cell is shown in Fig. 1(b). The parts have been built in the mechanical workshop of the University of Bayreuth. The plates are chromiumplated copper blocks of $70 \times 55 \times 11 \mathrm{~mm}^{3}$. Laterally, the sample volume is confined by a rectangular glass frame in optical quality (custom made by Hellma), which is partially inserted into milled grooves. The cell is sealed with two Viton o-rings between the copper plates and the glass frame. The glass frame is $3 \mathrm{~mm}$ high with overall dimensions of $50 \times 20 \times 5 \mathrm{~mm}^{3}$, corresponding to a path length of $40 \mathrm{~mm}$ along the optical axis. The vertical dimension $d$ of the cell, which defines the diffusion length and must be known very precisely, is defined by glass spacers that are clamped alongside the glass frame between the two copper plates $(d=1.022 \pm$ $0.002 \mathrm{~mm}$ ). In either plate, a calibrated temperature sensor (Epcos, B57540G103J) is mounted in a $1 \mathrm{~mm}$ hole at a distance of $1 \mathrm{~mm}$ from the boundary to the liquid. The cell is filled with syringes through two stainless-steel capillary tubes, soldered into the copper plates at two opposite corners of the cell.

The temperatures of the two plates can be set independently by two PID controllers (Wavelength Electronics, LFI-3751) with residual fluctuations of $\pm 1 \mathrm{mK}$. The plate temperatures are logged during the measurement at a rate of $10 \mathrm{~Hz}$ with a multimeter (Prema, DMM 5017), providing a resolution of $10^{-4} \mathrm{~K}$.

Contrary to the setup described in Ref. [33], we use a laser diode beam source (Schäfter + Kirchhoff $(\mathrm{S}+\mathrm{K})$, 51nanoFCM637) with a reduced coherence length of $300 \mu \mathrm{m}$, emitting at $637 \mathrm{~nm}$ and pigtailed to a single-mode optical fiber with 
collimator. In comparison to a helium-neon laser tube, this results in an increased beam pointing stability and avoids interference effects due to multiple reflexion at the glass frame and at the glass window in front of the detector. The beam is weakly focused into the sample cell by a collimator (S+K, 60FC-4-M5-33) with a focal range of $5.1 \mathrm{~mm}$. The focus has a diameter of $244 \mu \mathrm{m}$ for half height intensity (FWHM). After passing through the sample the laser spot is detected $1.5 \mathrm{~m}$ from the cell at the rear end of the rail by a CCD line camera (Spectronic Devices, OEM module). It provides 3648 pixel at a length of $29 \mathrm{~mm}$. Between cell and camera, the laser beam runs within a black anodized aluminum tube to avoid stray light on the detector and noise due to air turbulence.

All contrast factors $(\partial n / \partial T)_{p, c}$ and $(\partial n / \partial c)_{p, T}$ of the ethanol/water system, required for the determination of the Soret coefficient, were obtained by interferometric measurements as described in Ref. [34]. The contrast factors for the benchmark system had previously been measured in our laboratory and are published in Ref. [10]. A slight correction will be discussed below in the results section.

The water used in this work was purified with a Milli-Q de-ionization system. The ethanol (Riedel-de Haën, 99.8\%) and the three organic substances for the benchmark measurements, dodecane (Aldrich, 99+\%), 1,2,3,4-tetrahydronaphthalene (tetralin, Acros Organics, 98+\%), and isobutylbenzene (Aldrich, 99\%) were used without further purification.

\section{Results and Discussion}

In a typical experiment the whole setup is equilibrated at a constant temperature for at least five times the expected diffusion time constant. Then, rapid temperature jumps of $\delta T / 2$ and $-\delta T / 2$ are applied to the upper and the lower plate, respectively, by adjusting the set values of the temperature controllers correspondingly. Both plate temperatures and the beam position are recorded at a rate of $10 \mathrm{~Hz}$ over at least five diffusion time constants. For most measurements temperature differences of $\delta T=0.5 \ldots 1.0 \mathrm{~K}$ have been used. Typical signal traces for different $\delta T$ ranging from 0.05 to $1.0 \mathrm{~K}$ are shown in Fig. 2.

Data evaluation is based on the heat equation

$$
\frac{\partial T}{\partial t}=D_{t h} \Delta T
$$

for the temperature $T$ and the extended diffusion equation

$$
\frac{\partial c}{\partial t}=D \Delta c+D_{T} c(1-c) \Delta T
$$

for the weight fraction $c$ of component one. The diffusion coefficient $D$, the thermal diffusion coefficient $D_{T}$, and the thermal diffusivity $D_{t h}$ are taken as constant for a given experiment.

The laser beam is deflected due to the vertical (along the $z$-axis) gradient of the refractive index:

$$
\frac{\partial n}{\partial z}=\left(\frac{\partial n}{\partial T}\right)_{p, c} \frac{\partial T}{\partial z}+\left(\frac{\partial n}{\partial c}\right)_{p, T} \frac{\partial c}{\partial z}
$$

The time dependent values of $\partial T / \partial z$ and $\partial c / \partial z$ are obtained from the solutions of Eqs. 1 and 2 with the proper time dependent boundary conditions for the temper- 
ature.

The working equations for a standard beam deflection experiment have already been given by other authors [25]. Nevertheless, we briefly want to address the problem again and follow a slightly different approach in order to obtain two handy equations (Eqs. 4, 5) that can easily be extended to multiple layers with different thermal and optical properties. A practical application of this approach is the consistent treatment of the effect of temperature gradients within the cell windows.

A derivation of the deflection of a laser beam in a medium with arbitrary variation of the refractive index that is based on the eikonal equation can be found in Ref. [35]. With this formalism it can be shown that a beam traversing a layer of mean refractive index $n$ and length $l$ and with a perpendicular homogeneous refractive index gradient $\partial n / \partial z$ experiences, within linear approximation, a vertical displacement

$$
\delta z=\frac{l^{2}}{2 n} \frac{\partial n}{\partial z}+l \frac{n_{\text {air }}}{n} \theta_{i n}
$$

and a deflection

$$
\theta_{\text {out }}=\frac{l}{n_{\text {air }}} \frac{\partial n}{\partial z}+\theta_{\text {in }} .
$$

$\theta_{\text {in }} \ll 1$ is the angle between the incident beam and the optical axis ( $x$-axis) in air (refractive index $n_{\text {air }} \approx 1$ ) outside of the layer. The beam leaves the layer with an angle $\theta_{\text {out }} \ll 1$, again measured in air after taking Snell's law into account. Since all angles are measured within the same medium, the ambient air, multiple layers can easily be cascaded by taking $\theta_{\text {in }}$ of a particular layer equal to $\theta_{\text {out }}$ of the preceding one, thereby assuming an infinitely thin air gap between the two layers.

If we apply this procedure to the sequence consisting of entrance window (thickness $l_{w}$, refractive index $n_{w}$, refractive index gradient $\left.\partial n_{w} / \partial z\right)$, sample $(l, n$, $\partial n / \partial z)$, exit window $\left(l_{w}, n_{w}, \partial n_{w} / \partial z\right)$, and the space between the exit window and the detector $\left(l_{d}, n_{\text {air }}, \partial n_{\text {air }} / \partial z=0\right)$, we obtain for the beam displacement at the detector:

$$
\begin{aligned}
\delta z= & l \frac{\partial n}{\partial z}\left(\frac{l}{2 n}+\frac{l_{w}}{n_{w}}+\frac{l_{d}}{n_{\text {air }}}\right) \\
& +l_{w} \frac{\partial n_{w}}{\partial z}\left(\frac{l}{n}+\frac{2 l_{w}}{n_{w}}+\frac{2 l_{d}}{n_{\text {air }}}\right)
\end{aligned}
$$

For most organic liquids $(l \partial n / \partial z) \gg\left(l_{w} \partial n_{w} / \partial z\right)$, the second term on the right side can be neglected, and Eq. 6 reduces to the working equation for the beam deflection usually employed in the literature:

$$
\delta z=l \frac{\partial n}{\partial z}\left(\frac{l}{2 n}+\frac{l_{w}}{n_{w}}+\frac{l_{d}}{n_{\text {air }}}\right)
$$

Note that under certain circumstances, like for water in the vicinity of its density anomaly at $4{ }^{\circ} \mathrm{C}$, it may be necessary to take the second term in Eq. 6 as correction into account.

After the measurement, the transport coefficients $S_{T}, D$, and $D_{t h}$ are determined in an iterative procedure by comparing the measured deflection with the deflection calculated from the plate temperatures. The heat equation (1) and the diffusion equation (2) are numerically integrated for given values of the diffusion coefficients 
and with the measured plate temperatures as time dependent boundary conditions. $\partial n / \partial z$ is obtained from $T(z, t)$ and $c(z, t)$ according to Eq. 3. Due to its finite waist, the beam samples an inhomogeneous refractive index gradient, which is accounted for by averaging over the Gaussian beam profile $I(z)$ as suggested by Kolodner [23]:

$$
\left\langle\frac{\partial n}{\partial z}\right\rangle=\int_{0}^{d} \mathrm{~d} z \cdot I(z) \cdot \frac{\partial n}{\partial z}\left[\int_{0}^{d} \mathrm{~d} z \cdot I(z)\right]^{-1}
$$

The beam displacement is calculated with this average refractive index gradient according to Eq. 7.

The diffusion coefficients are determined by fitting the numerical solution to the measured beam deflection by a nonlinear least squares fitting routine with $D, D_{T}, D_{t h}$ and an amplitude factor as free parameters. As a cross-check, the stationary beam deflection amplitude of the pure temperature signal may also be calculated directly from $(\partial n / \partial T)_{p, c}$ and the measured temperature difference. It usually agrees with the measured value to within one percent. We found that the beam alignment parallel to the plates and within the symmetry plane of the cell is of utmost importance for correct measurements.

Fig. 2 shows, as an example, the beam deflection signal for an ethanol/water mixture ( 15 weight percent ethanol, $T=20^{\circ} \mathrm{C}$ ) for various temperature differences. Up to a temperature difference of $2 \mathrm{~K}$ no deviation from the linear model could be observed, and identical results were obtained for heating from above or from below. The fluctuations visible in the enlargement have an amplitude of approximately 0.1 percent of the signal and are due to temperature jitters caused by the temperature controllers. These are measured at the plates and propagate through the numerical integration into the fit curve. Hence, the fluctuations in Fig. 2 are to a large extent part of the signal and not noise. 


\section{Page 7 of 14 \\ Philosophical Magazine \& Philosophical Magazine Letters}

Table 1. Contrast factor $(\partial n / \partial T)_{p, c} / 10^{-4} \mathrm{~K}^{-1}$ for ethanol-water.

\begin{tabular}{cccccccccc}
\hline$T=$ & $10^{\circ} \mathrm{C}$ & $15^{\circ} \mathrm{C}$ & $20^{\circ} \mathrm{C}$ & $25^{\circ} \mathrm{C}$ & $30^{\circ} \mathrm{C}$ & $35^{\circ} \mathrm{C}$ & $40^{\circ} \mathrm{C}$ & $50^{\circ} \mathrm{C}$ & $60{ }^{\circ} \mathrm{C}$ \\
\hline$c$ & & & & & & & & & \\
0.0510 & -0.544 & -0.755 & -0.946 & -1.118 & -1.273 & -1.418 & -1.550 & -1.791 & -2.009 \\
0.1000 & -0.721 & -0.927 & -1.111 & -1.274 & -1.432 & -1.578 & -1.710 & -1.951 & \\
0.1520 & -1.034 & -1.214 & -1.385 & -1.537 & -1.685 & -1.821 & -1.949 & -2.180 & \\
0.1983 & -1.412 & -1.564 & -1.710 & -1.845 & -1.965 & -2.095 & -2.215 & -2.420 & \\
0.2512 & -1.878 & -1.995 & -2.115 & -2.225 & -2.328 & -2.427 & -2.520 & -2.712 & -2.865 \\
0.3016 & -2.275 & -2.360 & -2.445 & -2.531 & -2.614 & -2.690 & -2.770 & -2.928 & \\
0.3538 & -2.628 & -2.698 & -2.763 & -2.823 & -2.893 & -2.956 & -3.019 & -3.145 & -3.272 \\
0.3987 & -2.847 & -2.909 & -2.969 & -3.024 & -3.079 & -3.134 & -3.190 & -3.307 & \\
0.4998 & -3.170 & -3.231 & -3.274 & -3.320 & -3.375 & -3.426 & -3.479 & -3.592 & -3.736 \\
0.5921 & -3.393 & -3.438 & -3.487 & -3.536 & -3.589 & -3.632 & -3.690 & -3.809 & -3.932 \\
0.8968 & -3.934 & -3.970 & -4.010 & -4.050 & -4.093 & -4.142 & -4.197 & -4.294 & -4.448 \\
0.9437 & -3.981 & -4.014 & -4.045 & -4.075 & -4.121 & -4.167 & -4.216 & -4.329 & -4.461 \\
\hline
\end{tabular}

\section{Ethanol/Water}

Contrast factors

According to Eq. 3 the accuracy of the measured Soret coefficient critically depends on correct values for the contrast factors $(\partial n / \partial T)_{p, c}$ and $(\partial n / \partial c)_{p, T}$. Kolodner derived the temperature dependence of $n$ from the amplitude of the fast thermal contribution to the beam deflection signal [23]. While this is in principle feasible, we preferred to employ a completely independent interferometric technique for the measurement of $(\partial n / \partial T)_{p, c}$. This technique allows for an increased accuracy and an additional check of the performance of the beam deflection setup. Details of the interferometer and the data evaluation have been described in Ref. [10]. A slight correction well below $1 \%$ due to an improper treatment of a contribution from the window will be discussed below.

The measured $(\partial n / \partial T)_{p, c}$ values are summarized in Tab. 1 for the entire concentration range and for temperatures between 10 and $50^{\circ} \mathrm{C}$. The temperature dependence can well be parameterized by polynomials, but no simple fit function can be given for the concentration dependence. Where comparable to literature data, which cover only a more limited parameter range, there is an excellent agreement with the data of Wiegand [29], which have been measured with a similar interferometer. The data of Kolodner systematically show by one to two percent smaller absolute values [23].

The concentration derivative of the refractive index can, in principle, be determined by measuring $n$ as a function of $c$ and differentiation of a suitable interpolation function. Since it is not possible to find a polynomial of sufficiently low degree for $n(c)$ over the entire concentration range, and since the $3+1 / 2$-digits resolution of our Abbe-refractometer are barely sufficient, we measured $(\partial n / \partial c)_{p, T}$ directly as described in Ref. [34]. For this purpose, narrow-spaced concentration series centered around the concentration values of interest were prepared and subsequently injected into a scanning interferometer equipped with a flow cell. Evaluation of the phase shifts yields $(\partial n / \partial c)_{p, T}$. Since the scanning interferometer looses stability at elevated temperatures and since $(\partial n / \partial T)_{p, c}$ is known to a very high precision, only the $(\partial n / \partial c)_{p, T}$ data at $T_{0}=25^{\circ} \mathrm{C}$ have very carefully been measured by this laborious procedure. The values at different temperatures have been obtained by integrating $(\partial n / \partial T)_{p, c}$ over $T$ for every concentration $c$ and differentiating only this temperature dependent part, which can well be described by a 5th-order poly- 


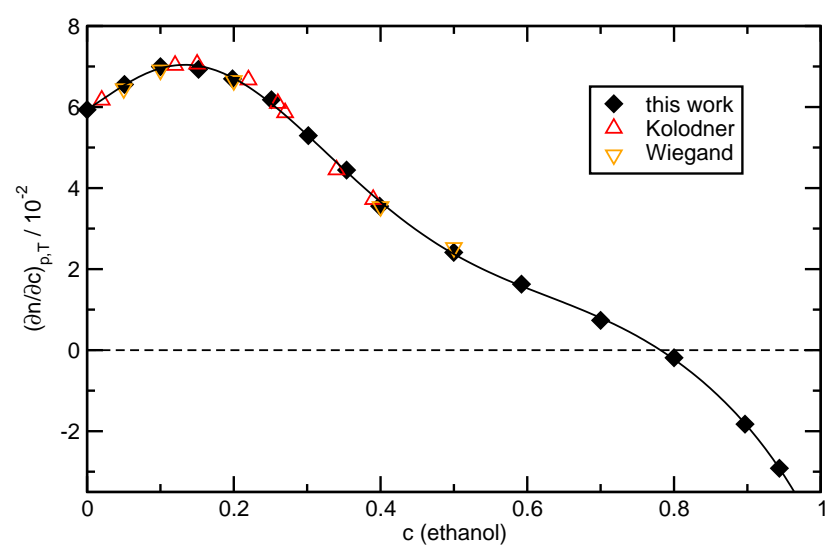

Figure 3. Contrast factors $(\partial n / \partial c)_{p, T}$ of ethanol/water for $T=25^{\circ} \mathrm{C}$. Literature values from Kolodner [23] and Wiegand [29].

Table 2. Contrast factor $(\partial n / \partial c)_{p, T} / 10^{-2}$ for ethanol-water.

\begin{tabular}{cccccccccc}
\hline$T=$ & $10^{\circ} \mathrm{C}$ & $15^{\circ} \mathrm{C}$ & $20^{\circ} \mathrm{C}$ & $25^{\circ} \mathrm{C}$ & $30^{\circ} \mathrm{C}$ & $35^{\circ} \mathrm{C}$ & $40^{\circ} \mathrm{C}$ & $50^{\circ} \mathrm{C}$ & $60^{\circ} \mathrm{C}$ \\
\hline$c$ & & & & & & & & & \\
0.0510 & 6.88 & 6.77 & 6.67 & 6.56 & 6.44 & 6.32 & 6.20 & 5.93 & 5.63 \\
0.1000 & 7.78 & 7.50 & 7.24 & 7.00 & 6.76 & 6.53 & 6.31 & 5.88 & 5.47 \\
0.1520 & 7.97 & 7.60 & 7.25 & 6.93 & 6.63 & 6.34 & 6.06 & 5.55 & 5.08 \\
0.1983 & 7.81 & 7.41 & 7.04 & 6.70 & 6.37 & 6.07 & 5.78 & 5.25 & 4.76 \\
0.2512 & 7.26 & 6.87 & 6.51 & 6.18 & 5.86 & 5.57 & 5.29 & 4.78 & 4.31 \\
0.3016 & 6.26 & 5.92 & 5.60 & 5.29 & 5.01 & 4.74 & 4.49 & 4.02 & 3.60 \\
0.3538 & 5.25 & 4.97 & 4.70 & 4.44 & 4.20 & 3.97 & 3.76 & 3.35 & 2.97 \\
0.3987 & 4.22 & 3.99 & 3.76 & 3.55 & 3.35 & 3.16 & 2.98 & 2.63 & 2.29 \\
0.4998 & 2.79 & 2.66 & 2.54 & 2.41 & 2.29 & 2.16 & 2.04 & 1.80 & 1.55 \\
0.5921 & 1.87 & 1.79 & 1.71 & 1.63 & 1.54 & 1.45 & 1.36 & 1.17 & 9.63 \\
0.7000 & 0.976 & 0.898 & 0.816 & 0.734 & 0.651 & 0.566 & 0.479 & 0.298 & 0.112 \\
0.8000 & 0.108 & 0.625 & -0.094 & -0.189 & -0.281 & -0.371 & -0.458 & -0.630 & -0.794 \\
0.8968 & -1.61 & -1.69 & -1.76 & -1.83 & -1.89 & -1.94 & -1.99 & -2.07 & -2.14 \\
0.9437 & -2.86 & -2.88 & -2.90 & -2.92 & -2.92 & -2.93 & -2.92 & -2.90 & -2.88 \\
\hline
\end{tabular}

nomial in $c$, with respect to concentration:

$$
\begin{aligned}
n(c, T) & =n\left(c, T_{0}\right)+\int_{T_{0}}^{T} d T^{\prime}\left(\frac{\partial n}{\partial T^{\prime}}\right)_{p, c} \\
\left(\frac{\partial n}{\partial c}\right)_{p, T} & =\left(\frac{\partial n}{\partial c}\right)_{p, T_{0}}+\frac{\partial}{\partial c} \int_{T_{0}}^{T} d T^{\prime}\left(\frac{\partial n}{\partial T^{\prime}}\right)_{p, c}
\end{aligned}
$$

The values of $(\partial n / \partial c)_{p, T=T_{0}}$ are plotted in Fig. 3 and the values for all temperatures and concentrations are summarized in Tab. 2. The agreement with the literature data, where available $[23,29]$, is somewhat less satisfactory than in case of the temperature dependence, with non-systematic deviations up to $3 \%$. Interestingly, the contrast factor changes its sign at ethanol concentrations around 0.8 , which renders measurements of $D$ and $S_{T}$ in this concentration range very difficult.

\section{Transport coefficients}

The diffusion coefficients obtained from the numerical analysis are plotted in Fig. 4 in comparison with literature data.

For $T=25^{\circ} \mathrm{C}$ there exist isothermal diffusion data of Hammond [36], who em- 


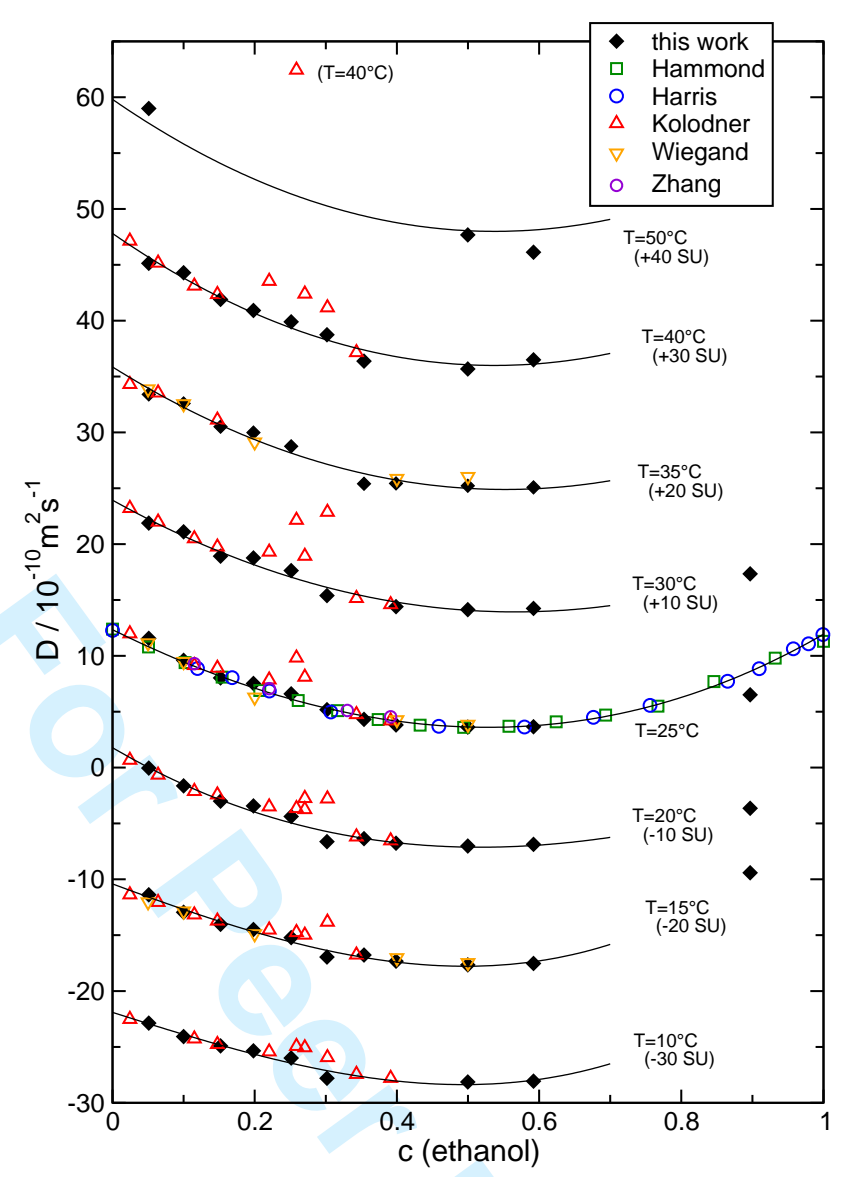

Figure 4. Diffusion coefficient $D$ of ethanol/water as a function of ethanol mass fraction at various temperatures. The y-axis corresponds to the data for $25^{\circ} \mathrm{C}$. The other temperatures are shifted in increments of 10 scale units (SU) along the y-axis. The solid lines are cubic polynomial fits to guide the eye. See text for references.

ployed a diaphragm cell, and of Harris [37], who used the Taylor dispersion technique. These two data sets are in excellent mutual agreement and show only very little scatter. Up to $c \approx 0.6$ also our own results and the ones of Wiegand $(c \leq 0.5)$ [29] are in perfect agreement with these data. The same is true for the values of Kolodner $(c \leq 0.39)$ [23], except for the three values at $c=0.220,0.259$, and 0.270, which deviate up to $50 \%$ from the common interpolating curve. Because of the vanishing signal at $c \approx 0.29$ (see below), measurements of $D$ become increasingly difficult around this concentrations.

For other temperatures no diaphragm cell or Taylor dispersion data are available. Otherwise, the pattern is similar to the situation at $25^{\circ} \mathrm{C}$ : our beam deflection data are in good agreement with the TDFRS measurements of Wiegand, where available, and with the beam deflection measurements of Kolodner, except for above mentioned problematic concentrations.

Up to $40^{\circ} \mathrm{C}$ reliable measurements could be performed. For completeness we have also included a few data points at $T=50^{\circ} \mathrm{C}$, but due to the high vapor pressure of ethanol the error bars increase considerably above this temperature. A few values at a high concentration $(c=0.897)$ are also plotted in Fig. 4. Because of the vanishing of the contrast factor at $c \approx 0.8$ and the small Soret coefficient, the corresponding errors are rather large, as can be judged from the deviation from the isothermal diffusion data at $T=25^{\circ} \mathrm{C}$.

Our results for the Soret coefficient $S_{T}$ are plotted as a function of concentration at different temperatures in Fig. 5 and the numerical values are tabulated in Tab. 
10

Table 3. Diffusion coefficient $D / 10^{-10} \mathrm{~m}^{2} \mathrm{~s}^{-1}$ for ethanol-water.

\begin{tabular}{cccccccccc}
\hline$T=$ & $10^{\circ} \mathrm{C}$ & $15^{\circ} \mathrm{C}$ & $20^{\circ} \mathrm{C}$ & $25^{\circ} \mathrm{C}$ & $30^{\circ} \mathrm{C}$ & $35^{\circ} \mathrm{C}$ & $40^{\circ} \mathrm{C}$ & $50^{\circ} \mathrm{C}$ & $60^{\circ} \mathrm{C}$ \\
\hline$c$ & & & & & & & & & \\
0.0510 & 7.13 & 8.62 & 9.95 & 11.57 & 11.88 & 13.41 & 15.14 & 19.00 & 20.60 \\
0.1000 & 5.92 & 7.05 & 8.36 & 9.60 & 11.11 & 12.59 & 14.30 & & \\
0.1520 & 5.09 & 5.98 & 7.00 & 8.03 & 8.93 & 10.51 & 11.91 & & \\
0.1983 & 4.65 & 5.51 & 6.57 & 7.53 & 8.76 & 9.99 & 10.91 & & \\
0.2512 & 4.00 & 4.78 & 5.63 & 6.60 & 7.64 & 8.76 & 9.90 & & \\
0.3016 & 2.19 & 3.04 & 3.37 & 5.18 & 5.40 & & 8.74 & & \\
0.3538 & & 3.23 & 3.64 & 4.32 & & 5.40 & 6.38 & & 8.95 \\
0.3987 & & 2.68 & 3.23 & 3.82 & 4.40 & 5.43 & & & \\
0.4998 & 1.86 & 2.34 & 2.98 & 3.62 & 4.13 & 5.22 & 5.68 & 7.68 & 12.80 \\
0.5921 & 1.93 & 2.47 & 3.13 & 3.66 & 4.25 & 5.08 & 6.50 & 6.13 & \\
0.8968 & & 10.59 & 6.36 & 2.51 & 1.34 & & & & \\
0.9437 & & 3.30 & 1.82 & & & & & 7.47 & \\
\hline
\end{tabular}

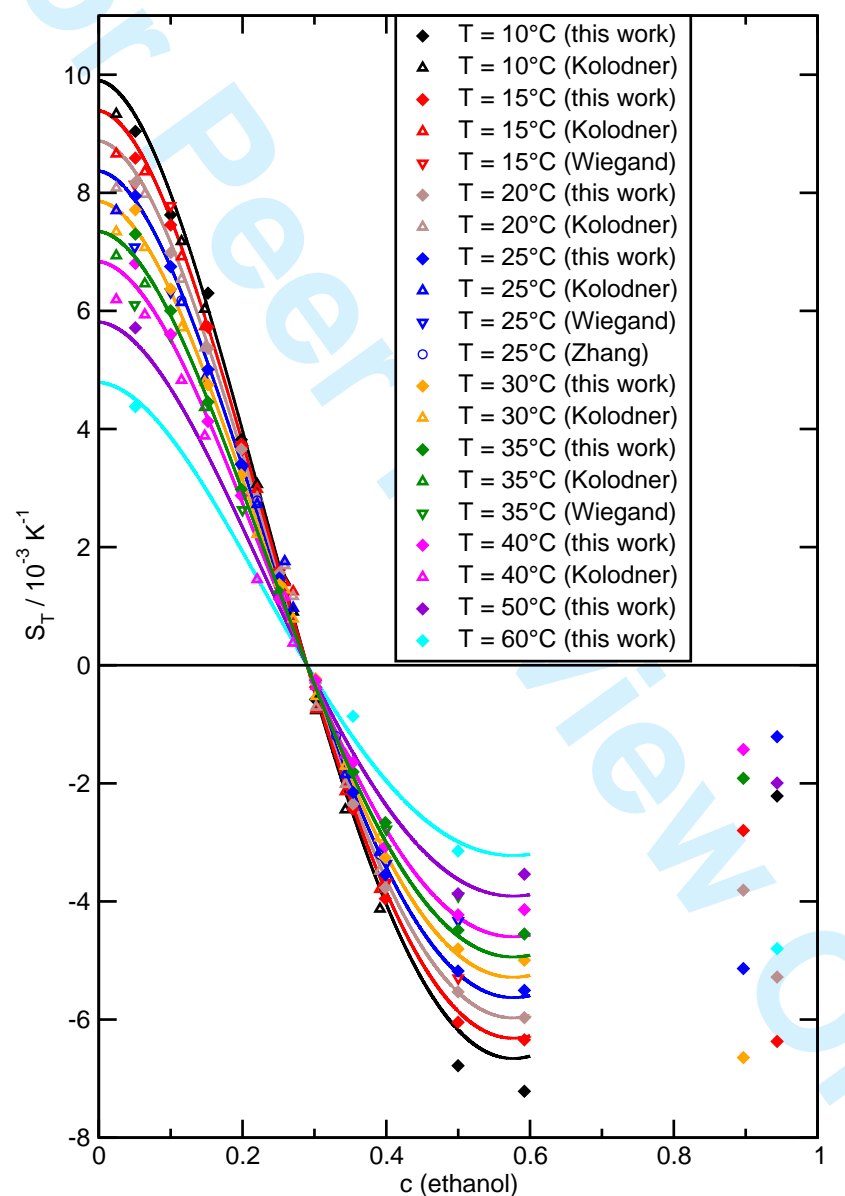

Figure 5. Soret coefficient $S_{T}$ of ethanol/water as a function of ethanol mass fraction at various temperatures. See text for references.

4. Included in Fig. 5 are data of Kolodner [23], Wiegand [29], and Zhang [25]. In general, the agreement between our results and the literature data, where available, is very good. Only at $c=0.051$ the values of Kolodner deviate noticeably, which might, at least partially, be explained by the different values for the contrast factors. The data of Wiegand deviate systematically towards smaller values by five percent. As for the diffusion coefficient, a few data points for high concentrations ( $c=$ 


\section{ebruary 4,2009
Page $\mathbf{1 1}$ of $\mathbf{1 4}$ \\ Philosophical Magazine \& Philosophical Magazine Letters}

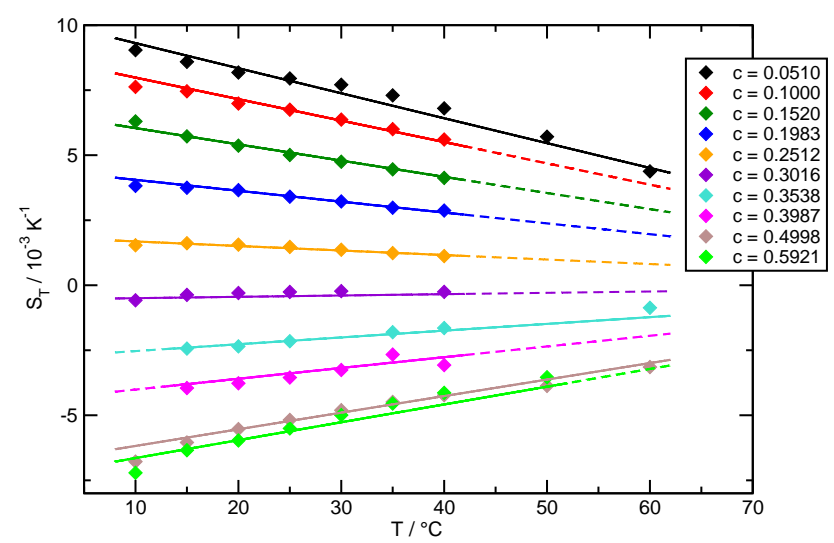

Figure 6. Soret coefficient $S_{T}$ of ethanol/water as a function of temperature for various ethanol concentrations $c$.

0.8968 and $c=0.9437)$ are included, but, due to the unfavorable contrast factor $(\partial n / \partial c)_{p, T} \approx 0$, the corresponding errors become very large and the number cannot sensibly be compared with the precise data for $c<0.6$. What can be said is that the Soret coefficient for concentrations above $c=0.29$ seems to remain negative throughout. Thus, only a bending up of $S_{T}$ but no evidence of a second sign change at higher ethanol concentrations, as speculated by Artola [31, 32], could be observed. In order to look for such a second sign change, we performed some additional measurements at an ethanol weight fraction $c=0.97$ for temperatures up to $70 \mathrm{~K}$ both by beam deflection and by TDFRS that are not included in the plots. Due to the extremely small signal amplitudes caused by both the small value of the contrast factor and the low concentration, no quantitative data could be obtained for $S_{T}$. Although we did not find any indication for a sign change of the concentration signal, we do not want to rule it out completely. It might be worth to perform a careful systematic study at even higher ethanol concentrations and higher temperatures, possibly in a pressurized cell, but this is a rather difficult task. Note that, although there is no second sign change of $S_{T}$, there is, a sign change of $(\partial n / \partial c)_{p, T}$ in this concentration range.

The solid curves result from a least squares fit of an empirical factorization of $S_{T}$ into a concentration dependent function with a temperature dependent amplitude factor proposed by Wittko [38]:

$$
S_{T}=S_{T}^{0}+\alpha(c) \beta(T)
$$

$\alpha(c)=\left(11.46-15.36 c-145.3 c^{2}+237.8 c^{3}-65.16 c^{4}\right) \mathrm{K}^{-1}$ is a $4^{\text {th }}$ order polynomial in $c$ and $\beta(T)=1-0.00931 \mathrm{~K}^{-1} T$. This product form with a temperature independent fixed point $S_{T}^{0} \approx 0$ at $c=0.290$ yields a remarkably good, although not perfect, description of the data. This can also be seen in Fig. 6, where our $S_{T}$-data are plotted as a function of temperature for every concentration, together with the fit curves from Eq. 11.

It should be kept in mind that there are two concentrations where optical measurements of $D$ and $S_{T}$ become difficult. The first is at $c \approx 0.29$, where the Soret coefficient vanishes. While this is no problem for $S_{T}$, for which the absolute error remains constant, the vanishing signal amplitude leads to a strong increase of the uncertainty of $D$. This can be seen by the larger scatter of the data of Kolodner around this concentration in Fig. 4. In particular for small signals, a complete mathematical model of the measurement process, as demonstrated by the insert in Fig. 2, is of importance. The second problematic concentration is at $c \approx 0.78$, 
Table 4. Soret coefficient $S_{\mathrm{T}} / 10^{-3} \mathrm{~K}^{-1}$ for ethanol-water.

\begin{tabular}{cccccccccc}
\hline$T=$ & $10^{\circ} \mathrm{C}$ & $15^{\circ} \mathrm{C}$ & $20^{\circ} \mathrm{C}$ & $25^{\circ} \mathrm{C}$ & $30^{\circ} \mathrm{C}$ & $35^{\circ} \mathrm{C}$ & $40^{\circ} \mathrm{C}$ & $50^{\circ} \mathrm{C}$ & $60^{\circ} \mathrm{C}$ \\
\hline$c$ & & & & & & & & & \\
0.0510 & 9.04 & 8.59 & 8.18 & 7.71 & 7.95 & 7.30 & 6.80 & 5.71 & 4.38 \\
0.1000 & 7.63 & 7.46 & 6.99 & 6.75 & 6.37 & 6.00 & 5.60 & & \\
0.1520 & 6.30 & 5.72 & 5.37 & 5.01 & 4.75 & 4.46 & 4.13 & & \\
0.1983 & 3.82 & 3.75 & 3.66 & 3.41 & 3.22 & 2.98 & 2.87 & & \\
0.2512 & 1.54 & 1.61 & 1.56 & 1.47 & 1.37 & 1.24 & 1.12 & & \\
0.3016 & -0.58 & -0.37 & -0.30 & -0.26 & -0.23 & & -0.254 & & \\
0.3538 & & -2.44 & -2.35 & -2.15 & & -1.51 & -1.15 & & -0.87 \\
0.3987 & -2.97 & -3.95 & -3.77 & -3.55 & -3.26 & -2.67 & -3.07 & & \\
0.4998 & -6.78 & -6.05 & -5.53 & -5.18 & -4.80 & -4.49 & -4.23 & -3.87 & -3.14 \\
0.5921 & -7.21 & -6.34 & -5.97 & -5.51 & -4.99 & -4.55 & -4.14 & -3.54 & \\
0.8968 & & -2.80 & -3.81 & -5.14 & -6.64 & -1.92 & -1.43 & & \\
0.9437 & -2.21 & -6.37 & -5.28 & -1.21 & -0.102 & & & -20.0 & \\
\hline
\end{tabular}

where $(\partial n / \partial c)_{p, T}$ vanishes. Around this concentration, neither $D$ nor $S_{T}$ can be determined with acceptable accuracy.

\section{Benchmark Systems}

After the investigation of ethanol/water, the second purpose of this work was the so far missing measurement of the organic benchmark systems by the beam deflection technique. The measurements for the three binary mixtures of dodecane, isobutylbenzene and 1,2,3,4-tetrahydronaphthalene of 50 percent weight fraction at a temperature of $T=25{ }^{\circ} \mathrm{C}$ was performed almost in the same way as for the ethanol/water mixtures. The only change was the reduced temperature difference of only $0.2 \mathrm{~K}$ between the two plates because of the higher $(\partial n / \partial T)_{p, c}$ of the organic solvents.

The contrast factors had previously been determined in our laboratory for the TDFRS measurements [10], and these values have also been used for the beam deflection experiment. There is only a minor correction for the $(\partial n / \partial T)_{p, c}$ values. In Refs. $[10,34]$ we calculated the correction term for the cell windows based on the Lorentz-Lorenz equation. This procedure is, however, only valid for liquids but not for the glass material, and the temperature dependence of the refractive index of the cell windows must be taken from the data sheet supplied by the manufacturer of the glass. The correction for the measured $(\partial n / \partial T)_{p, c}$ values is, however, well below one percent [39].

Table 5 contains the contrast factors used and the measured $D, D_{T}$, and $S_{T}=$ $D_{T} / D$. For comparison, the table also contains the proposed benchmark values, which were obtained as an average over all experimental techniques contributing to Ref. [9]. Generally, the agreement of the beam deflection measurement with these reference values is very good. The largest deviation is observed for the diffusion coefficient of 1,2,3,4-tetrahydronaphthalene/isobutylbenzene. For this system the signal is particularly weak and it also shows the largest scatter between the single experiments of the benchmark campaign, where the measured diffusion coefficients ranged from 7.9 to $9.05 \times 10^{-10} \mathrm{~m}^{2} / \mathrm{s}$. Motivated by the good agreement, we have computed new averages that are based on the original benchmark experiments in Ref. [9] and the newly available beam deflection results, thus increasing the experimental basis of and the confidence in the benchmark values. These new averages, which differ only slightly from the originally proposed benchmark values, 
are also included in Tab. 5 .

\section{Summary and Conclusion}

We have built an optical beam deflection setup for the measurement of isothermal diffusion, thermal diffusion, and Soret coefficients in binary liquid mixtures. The design closely resembles the one developed in the group of Piazza, which we copied in a first step. The instrument could be improved by a number of modifications, such as the use of a fibre coupled laser with very short coherence length and a full numerical model of the generated signal. In a first step the performance of the instrument was tested with ethanol/water mixtures, for which reliable literature data for a broad temperature range and concentrations up to 40 (Kolodner) and 50 ethanol weight percent have been available. Generally, a very good agreement between our own measurements and the literature data could be achieved, with improved values of the diffusion coefficient in the range where the Soret coefficient changes its sign. Since the Soret coefficient can only be known to the same accuracy as the contrast factors, we performed additional precise interferometric measurements of both $(\partial n / \partial T)_{p, c}$ and $(\partial n / \partial c)_{p, T}$, which resulted in modified values of the Soret coefficient. Measurements over a broad concentration range, albeit difficult at high ethanol concentrations because of the sign change and the small absolute value of $(\partial n / \partial c)_{p, T}$, did not reveal a second sign change of $S_{T}$, as had been speculated before. The good agreement between different authors and for different experimental techniques makes ethanol/water to one of the best characterized reference systems for Soret coefficients. Contrary to the organic benchmark systems, data are available over a broad temperature and concentration range. After the thorough investigation of ethanol/water, the beam deflection setup was used to supply the still missing data for the benchmark systems consisting of the symmetric binary mixtures of dodecane, isobutylbenzene, and 1,2,3,4-tetrahydronaphthalene. Also here, a very good overall agreement with the proposed values has been achieved. Given these results, an open gap in the benchmark data has been closed and it has convincingly been demonstrated that correct Soret coefficients can be measured under gravity conditions with all major ground based experimental techniques. 


\section{Acknowledgement}

We thank R. Piazza for his hospitality and help with the beam deflection setup, A. Krekhov for assistance with the numerical analysis, and S. Hartmann for TDFRS measurements. The work was supported by Deutsche Forschungsgemeinschaft (DFG) (Ko 1541/5-2).

\section{References}

[1] P. Costesèque, D. Fargue and P. Jamet, Thermodiffusion in porous media and its consequences, in Thermal Nonequilibrium Phenomena in Fluid Mixtures, W. Köhler and S. Wiegand, eds., Springer, Heidelberg, 2002, p. 389.

[2] J.J. Gunderson and J.C. Giddings, Macromolecules 19 (1986) p.2618.

[3] M.E. Schimpf and J.C. Giddings, J. Polym. Sci.: Part B: Polym. Phys. 27 (1989) p.1317.

[4] P. Kolodner, A. Passner, C.M. Surko and R.W. Walden, Phys. Rev. Lett. 56 (1986) p.2621.

[5] D. Braun and A. Libchaber, Phys. Rev. Lett. 89 (2002) p.188103.

[6] C. Ludwig, Sitzber. Akad. Wiss. Wien Math.-naturw. Kl. 20 (1856) p.539.

[7] C. Soret, Arch. Sci. Phys. Nat. Geneve 2 (1879) p.48.

[8] S. Van Vaerenbergh and J.C. Legros, J. Phys. Chem. B 102 (1998) p.4426.

[9] J.K. Platten, M.M. Bou-Ali, P. Costesèque, J.F. Dutrieux, W. Köhler, C. Leppla, S. Wiegand and G. Wittko, Philos. Mag. 83 (2003) p.1965.

[10] G. Wittko and W. Köhler, Philos. Mag. 83 (2003) p.1973.

[11] C. Leppla and S. Wiegand, Philos. Mag. 83 (2003) p.1989.

[12] M.M. Bou-Ali, J.J. Valencia, J.A. Madariaga, C. Santamaría, O. Ecenarro and J.F. Dutrieux, Philos. Mag. 83 (2003) p.2011.

[13] J.K. Platten, M.M. Bou-Ali and J.F. Dutrieux, Philos. Mag. 83 (2003) p.2001.

[14] P. Costesèque and J.C. Loubet, Philos. Mag. 83 (2003) p.2017.

[15] W. Köhler and P. Rossmanith, J. Phys. Chem. 99 (1995) p.5838.

[16] S.A. Putnam and D.G. Cahill, Rev. Sci. Instr. 75 (2004) p.2368.

[17] M. Hartung and W. Köhler, Rev. Sci. Instr. 78 (2007) p.084901.

[18] S. Wiegand, J. Phys. Condens. Matter 16 (2004) p.R357.

[19] K. Nachtigall and G. Meyerhoff, Macromol. Chem. 33 (1959) p.85.

[20] G. Meyerhoff and K. Nachtigall, J. Polym. Sci. 57 (1962) p.227.

[21] M. Giglio and A. Vendramini, Phys. Rev. Lett. 34 (1975) p.561.

[22] M. Giglio and A. Vendramini, Phys. Rev. Lett. 38 (1977) p.26.

[23] P. Kolodner, H. Williams and C. Moe, J. Chem. Phys. 88 (1988) p.6512.

[24] K.J. Zhang, M.E. Briggs, R.W. Gammon, J.V. Sengers and J.F. Douglas, J. Chem. Phys. 111 (1999) p. 2270 .

[25] K.J. Zhang, M.E. Briggs, R.W. Gammon and J.V. Sengers, J. Chem. Phys. 104 (1996) p.6881.

[26] R. Piazza, S. Iacopini and B. Triulzi, Phys. Chem. Chem. Phys. 6 (2004) p.1616.

[27] J.A. Bierlein, J. Chem. Phys. 23 (1955) p.10.

[28] Y. Yu, C.L. Chan and C.F. Chen, J. Fluid Mech. 589 (2007) p.183.

[29] S. Wiegand, H. Ning and H. Kriegs, J. Phys. Chem. B 111 (2007) p.14169.

[30] J.K. Platten, M.M. Bou-Ali, P. Blanco, J.A. Madariaga and C. Santamaria, J. Phys. Chem. B 111 (2007) p.11524.

[31] P.A. Artola and B. Rousseau, Phys. Rev. Lett. 98 (2007) p.125901.

[32] P.A. Artola, B. Rousseau and G. Galliero, J. Am. Chem. Soc. 130 (2008) p.10963.

[33] R. Piazza, Philos. Mag. 83 (2003) p.2067.

[34] A. Becker, W. Köhler and B. Müller, Ber. Bunsenges. Phys. Chem. 99 (1995) p.600.

[35] M.V. Klein Optics, Wiley, New York, 1970.

[36] B.R. Hammond and R.H. Stokes, Trans. Faraday Soc. 49 (1953) p.890.

[37] K.R. Harris, T. Goscinska and H.N. Lam, J. Chem. Soc. Faraday Trans. 89 (1993) p.1969.

[38] G. Wittko and W. Köhler, Europhys. Lett. 78 (2007) p.46007.

[39] J. Rauch and W. Köhler, J. Chem. Phys. 119 (2003) p.11977. 